\title{
Size Fractionation by Slalom Chromatography and Hydrodynamic Chromatography
}

\author{
Ricardo P. Dias ${ }^{\mathrm{a}, \mathrm{b} *}$ \\ ${ }^{a}$ Department of Chemical and Biological Technology, Escola Superior de Tecnologia e de Gestão, Instituto Politécnico \\ de Bragança, Campus de Santa Apolónia, 5301-854 Bragança, Portugal, ${ }^{b}$ CEFT - Centro de Estudos de Fenómenos de \\ Transporte, Faculdade de Engenharia da Universidade do Porto, Rua Dr. Roberto Frias, 4200-465 Porto, Portugal
}

Received: April 6, 2008; Accepted: May 6, 2008; Revised: May 16, 2008

\begin{abstract}
Hydrodynamic chromatography, also called separation by flow, is based on the use of the parabolic flow profile occurring in open capillaries or in the pores from a column filled with non-porous particles. The hydrodynamic chromatography separation medium, if any, is much simpler than that from size exclusion chromatography (porous particles), the former technique being used in the size-fractionation of many colloids and macromolecules. The transition between hydrodynamic chromatography (obtained using low flow rates) and slalom chromatography (obtained using high flow rates) was reported in studies related with the migration behaviour of proteins, plasmid DNAs and double stranded DNAs. Slalom chromatography is mainly applied in the size-fractionation of large double stranded DNA fragments and may compete with electrophoretic techniques. In the present paper it is discussed the main patents, applications, advantages and drawbacks related to hydrodynamic chromatography and slalom chromatography, as well as some strategies that may improve the performance of these simple size-fractionation techniques.
\end{abstract}

Keywords: Separation by flow, hydrodynamic chromatography, slalom chromatography, particle size distribution, synthetic polymers, biopolymers, starch, DNA.

\section{INTRODUCTION}

The size fractionation of polymers or particles by hydrodynamic chromatography (HDC) was suggested four decades ago by DiMarzio and Guttman [1], using a theoretical approach. Meanwhile, it was found application for HDC in a broad range of separations such as polymer latexes [2,3], rigid and flexible polymers [4-13], silica particles[14], zeolites [15], viruses [5], bacteria and yeasts [16], proteins [17], plasmid DNAs [17,18], starch [19,20], gold colloids [21], liposomes[21] and nanocapsules [22], these separations being performed using columns packed with nonporous particles (packed-column hydrodynamic chromatography (PCHDC)) or in open capillaries (capillary hydrodynamic chromatography (CHDC)).

The transition between HDC (obtained for low flow rates) and slalom chromatography (obtained for high flow rates) was observed in different works [17,18, 23, 24] using proteins, plasmid DNAs and large double stranded DNAs. HDC and slalom chromatography (SC) belong to a class of chromatographic techniques called non equilibrium chromatography since they can't be explained by an equilibrium constant between the stationary and mobile phase [17, 18, 23, 24].

SC was discovered two decades ago by two independent groups $[25,26]$, being found that large fragments of double stranded DNAs were separated according to size due to a hydrodynamic phenomenon. In SC the DNA molecules elution order is the opposite of that expected for an HDC

\footnotetext{
*Address correspondence to this author at the Department of Chemical and Biological Technology, Escola Superior de Tecnologia e de Gestão, Instituto Politécnico de Bragança, Campus de Santa Apolónia, 5301-854 Bragança, Portugal; Tel: +351273303150; Fax: +351273313051; E-mail: ricardod@ipb.pt
}

mechanism, since in SC the larger DNA strands are eluted after the smaller ones [27-33].

\section{SEPARATION MECHANISMS}

Most of the theories from PCHDC have been derived from the model as used to describe the migration, under laminar regime, of polymers or particles in CHDC (Fig. (1)).

As a result of Brownian motion, the molecules/particles with effective radius, $\phi$, will diffuse over all possible radial locations, this radial diffusion being fast enough to transport many times the molecules/particles over the capillary cross section during their residence time in the tube $[1,6]$.

Due to their finite size, the molecules/particles centre of gravity cannot approach the capillary (with radius $R$ ) wall closer than their own effective radius (Fig. (1)). Large molecules/particles will experience higher velocities (observed in the range $R-\phi$ ) from the parabolic flow when compared with the infinite small molecules/particles that experience all the stream lines available in the column cross section. As a result of this, large molecules/particles will migrate faster (if the ratio $\lambda=\phi / R$ is not too large) through the column than small molecules/particles $[1,6]$.

The ratio $\lambda=\phi / R$ is the key parameter in the HDC separations since molecules/particles with different values of $\lambda$ will migrate at different velocities, this allowing the size fractionation. Despite of this, it is important to note that when the particles are immersed in a parabolic flow, the side of the particle that is closer to the capillary centre (Fig. (1)) is located on a streamline with higher velocity $\left(u\left(r_{2}\right)\right)$ than the side closest to the capillary wall $\left(u\left(r_{l}\right)\right)$. Therefore the particle/molecule rotates and this movement affects the translational velocity $[1,6]$. 


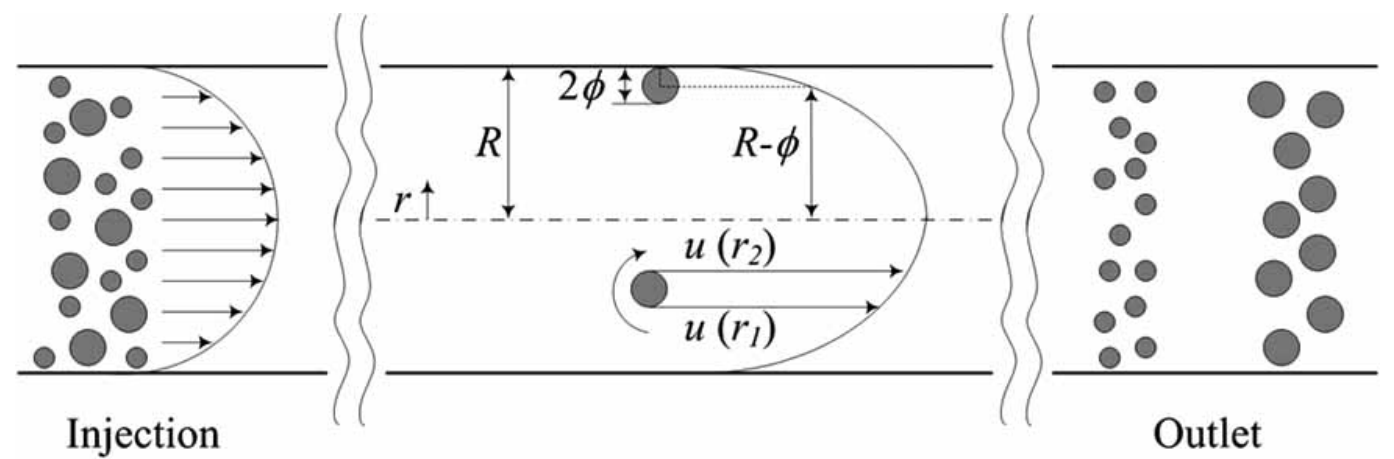

Fig. (1). HDC separation mechanism. The cylindrical capillary has a radius $R$ and $u(r)$ represents the local velocity for a stream line at a radial position $r$.

The different effects mentioned above are included in the following model [1, 6-8]:

$R R T=\frac{1}{1+2 \lambda-C \lambda^{2}}$

$R R T$ being the relative retention time, defined as the ratio between the average residence time of a molecule/particle with effective radius $\phi$ and the average residence time of a molecule/particle with infinite small size (the infinite small sized marker), $R R T$ being $\leq 1$. For cylindrical capillaries, constant $C$ varies between 1 and 5, assuming a value of 2.7 for different flexible polymers and a value of 4.89 for solid spherical particles [34].

The modelling of transport of flexible polymers is much more complex than that of rigid spherical particles since the size and shape of the polymer are not well defined, being difficult to predict the distance (effective radius) to which the mass centre of the polymer can approach the wall of the capillary [7].

Using CHDC columns with internal diameters around 1 $\mu \mathrm{m}$, Tijssen et al. (1986) [6] separated flexible linear random coil polystyrenes with different molecular weight $(M w)$. Stegeman et al. (1993) [7] used PCHDC columns packed with non-porous glass spheres with diameter $1.5 \mu \mathrm{m}$ and separated by HDC different $M w$ flexible polymers (polystyrene, polyisoprene, polyisobutadiene). Non-porous glass spheres with diameter $1 \mu \mathrm{m}$ were used by Venema et al. [8] in the separation of different $M w$ polysterenes and poly(methyl methacrylate). In these different works it was found that $\phi$ was well described by $(\sqrt{\pi} / 2) R_{g}, R_{g}$ being the gyration radius from the polymers.

Using this effective radius definition and $C=2.7$, the different authors [6-8] found that the $R R T$ experimental values were well described by Eq. (1). Therefore, Eq. (1) could be used as a universal calibration curve (Fig. (2)) for the studied flexible polymers, as in size exclusion chromatography [7].

In Fig. (2) it can also be observed that the $R R T$ starts to increase with the increase of $\lambda$ when this parameter is higher than $\sim 0.35$. Thus, for values of $\lambda$ higher than $\sim 0.35$, small molecules migrate faster through the column than large molecules, this fact being reported in different experimental

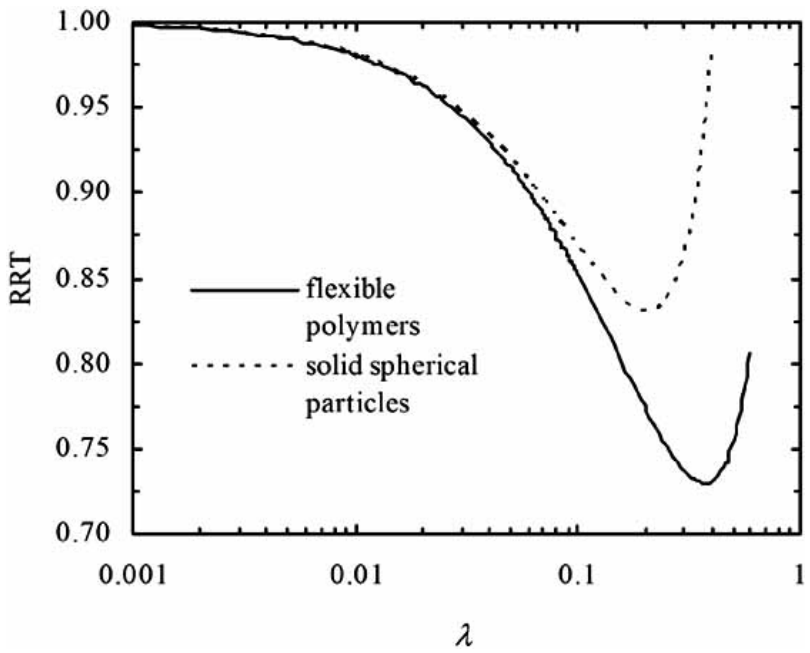

Fig. (2). RRT for different values of $\lambda$. The curves for flexible polymers and solid spherical particles were obtained using $C=$ 2.7 and $C=4.89$ [34] in Eq. (1), respectively.

works [6-8]. For values of $\lambda$ large enough, the polymer will be trapped in the separation medium.

The RRTs from solid spherical particles and flexible polymers (Fig. (2)) are significantly different for values of $\lambda$ superior to $\sim 0.1$. The value of $C$ for micelles is not known but it is expected to be between $C=2.7$ and $C=4.89$ [34].

In works $[7,8,11,14]$ where PCHDC was used, it was assumed that the interstitial channels could be represented by a bundle of cylindrical capillaries with average radius, $R$, given by $\left(d_{p} / 3\right)(\varepsilon /(1-\varepsilon)), d_{p}$ being the particle diameter and $\varepsilon$ the packing porosity. Since $\phi$ is given by $(\sqrt{\pi} / 2) R_{g}$ and $R_{g}$ can be calculated resorting to the $R_{g}-M w$ relationships (available in the literature or determined experimentally), Eq. (1) can be used to estimate the $M w$ from the flexible polymer after measuring the $R R T$ of the polymer.

For a given polymer, the experimental RRTs can be easily determined (Fig. (3)). In this figure it is shown the average residence time of sucrose (curve $a$ ) - the chosen infinite small sized marker - and the average residence time of pullulans with $M w 200 \mathrm{kDa}$ (curve $b$ ) - a gift from 


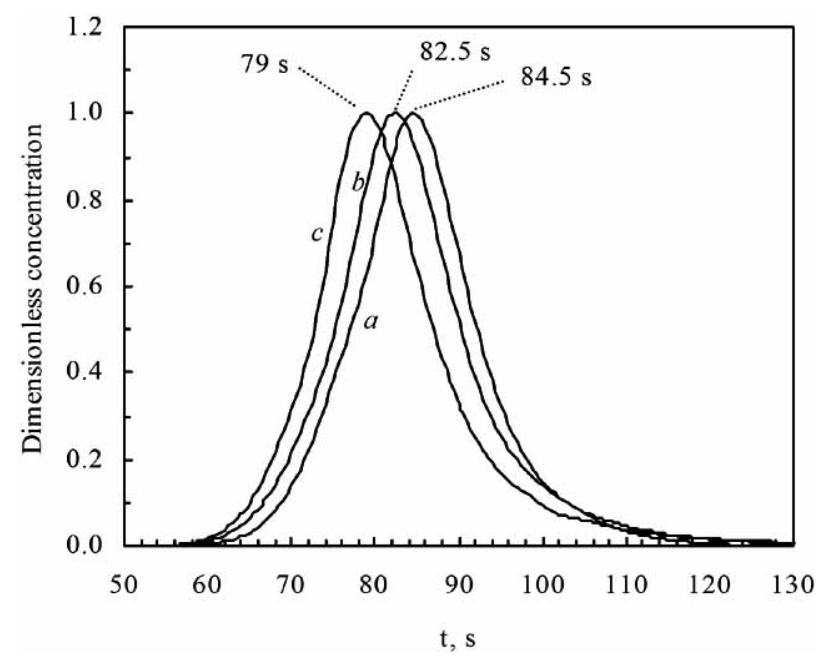

Fig. (3). Elution profiles of different $M w$ pullulans and sucrose at a flow rate $1 \mathrm{mLmin}^{-1}$ [20]: (a) sucrose; (b) pullulan with $M w 200$ $\mathrm{kDa}$; (c) pullulan with $M w 788 \mathrm{kDa}$. The column was packed with a mixture of non-porous glass spheres: $65 \%$ with diameter $5 \mu \mathrm{m}$ and $35 \%$ with diameter $19 \mu \mathrm{m}$.

Hayashibara Co., Ltd - and $M w 788 \mathrm{kDa}$ (curve $c$ ). The experimental values (Fig. (3)) of the $R R T$ are $0.976(82.5 /$ $84.5)$ and $0.935(79 / 84.5)$ for the pullulans with $M w 200 \mathrm{kDa}$ and $788 \mathrm{kDa}$, respectively.

The solvent and the mobile phase was water, the column had dimensions $200 \times 4.6 \mathrm{~mm}$ ID and was packed with a mixture of glass spheres $(65 \%$ with diameter $5 \mu \mathrm{m}$ and $35 \%$ with diameter $19 \mu \mathrm{m})$, the average particle size [35-40] being $9.6 \mu \mathrm{m}, \varepsilon=0.316$ and, therefore, the average pore radius, $R$, being $1.478 \mu \mathrm{m}$. Pullulan is a flexible random coil exopolysaccharide [41] and the $R_{g}-M w$ relationship is $R_{g}=1.47 \times 10^{-5}(M w)^{-0.58} \quad[41]$ the values of $\phi$ $\left((\sqrt[3]{\pi} / 2) R_{g}\right)$ being $0.0155 \mu \mathrm{m}$ and $0.0343 \mu \mathrm{m}$ for $M w=200$ $\mathrm{kDa}$ and $788 \mathrm{kDa}$, respectively. Therefore, the values of $\lambda$ are 0.0105 and 0.0232 for the pullulans with $M w 200 \mathrm{kDa}$ and $788 \mathrm{kDa}$, respectively. Using these values of $\lambda$ and Eq. (1) $(C=2.7)$ the predicted values of the $R R T$ are 0.980 and 0.957 for the pullulans with $M w 200 \mathrm{kDa}$ and $788 \mathrm{kDa}$, respectively. These $R R T$ values are in good agreement with the experimental ones (0.976 and 0.935).

The packed bed reported in Fig. (3) was used by Dias [20] and Dias et al. [38] to separate amylose and amylopectin - by PCHDC - present in different commercial starches (gifts from National Starch \& Chemical). The large molecules of amylopectin [42-50] eluted first and the resolution was similar to that obtained with size exclusion chromatography.

The experimental $R R T$ values from Stegeman et al. [7] were in good agreement with the calibration curve $(C=2.7)$ shown in Fig. (2) for average velocities bellow $0.22 \mathrm{mms}^{-1}$. For higher velocities it was observed that the random coils were elongated (coil-stretch transition [12, 13]) since the hydrodynamic or elongation forces were no longer compensated by the forces of chain relaxation that arise from Brownian motion [5]. Since $\phi$ is a characteristic length transverse to the direction of flow, polymer stretching in the flow direction leads to a decrease of $\lambda$ and, therefore, to the increase of the $R R T$ [5].

Large double stranded DNA molecules possess a dynamic behaviour in solution. A random coil state and a stretched state can be observed in the absence and presence of an external force (hydrodynamic flow), respectively, due to the DNA elastic property $[27,32]$. In SC, large $(\sim 5$ to 50 $\mathrm{kbp})$ double stranded DNA molecules and a relative fast flow rate $\left(\sim 0.3\right.$ to $\left.2 \mathrm{mLmin}^{-1}\right)$ are applied to a packed column ( 4.6 to $7.6 \mathrm{~mm}$ ID), the DNA molecules having a coiled state being progressively elongated. Long DNA strands must turn many times around packing particles and one each turn they are exposed to a considerable frictional force. This force increases with the increase of DNA length, larger DNA molecules being more retarded [27-33].

In SC the elution order of DNA molecules is the contrary to that expected for a HDC mechanism since in the former technique the larger DNA molecules migrate slower than the smaller ones. Therefore, in SC the values of the $R R T$ are $\geq 1$ (Fig. (4)). As already referred, the transition between HDC (obtained using low flow rates) and SC (obtained using high flow rates) was recently noticed [17, 18, 23, 24].

Experimental work [26-31] proved that the chemical nature of the packing particles, the porous media pore size and solvent hydrophobicity were not important in SC. On the other hand, various hydrodynamic factors affected DNA retardation. Retardation is superior (higher $R R T$ ) when the temperature [27, 29, 31] and viscosity [29, 30] (Fig. (4a)) from the mobile phase decreases and increases, respectively. Obviously, the liquid temperature and viscosity are related and a viscosity increase leads to a higher hydrodynamic force originated by the mobile phase [29, 30] but a temperature decrease can also lead to the enhancement of the DNA steady-state extension [31].

The influence of the mobile phase temperature and viscosity on DNA retardation is well described by the semitheoretical model from Peyrin et al. [32]. In addition, this model can be used to predict the influence of the packing particle diameter (typically located in the range range 2.5 $20 \mu \mathrm{m}[25-33])$ and mobile phase flow rate, $F$, on the $R R T$ [32]:

$R R T=\left(1-K_{1}\left(L / d_{p}\right)\right)^{-1}$
$R R T=\left(K_{2} \frac{L}{d_{p}}\left(e^{K_{3} d_{p} / L}-1\right)\right)^{-1}$

In Eqs. (2) and (3) $K_{1}, K_{2}$ and $K_{3}$ are empirical constants dependent from the structural arrangement of the spherical particles (with diameter $d_{p}$ ) inside the column. $L$ represents the steady-state extension of the DNA chain and can be estimated using a theoretical approach [32]. Eq. (2) may be used bellow the critical steady-state extension [32], $L_{c}$ :

$L_{c}=d_{p} K_{3} \ln \left(\frac{1}{K_{2} K_{3}}\right)$

and Eq. (3) may be used above $L_{c}$. 
The use of columns packed with smaller particles allows the separation of smaller DNA strands (Eq. (2)), as sketched in Fig. (4b). In a packing containing small particles (Fig. (4b)) it can be identified three zones according to slope. Higher resolutions can be obtained in the middle zone, since a steepest slope is observed in that region [27].

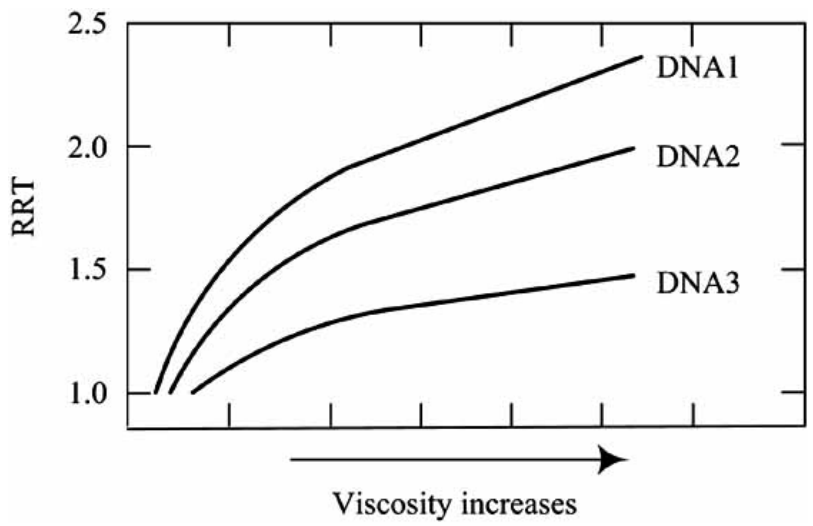

$4 \mathbf{a}$

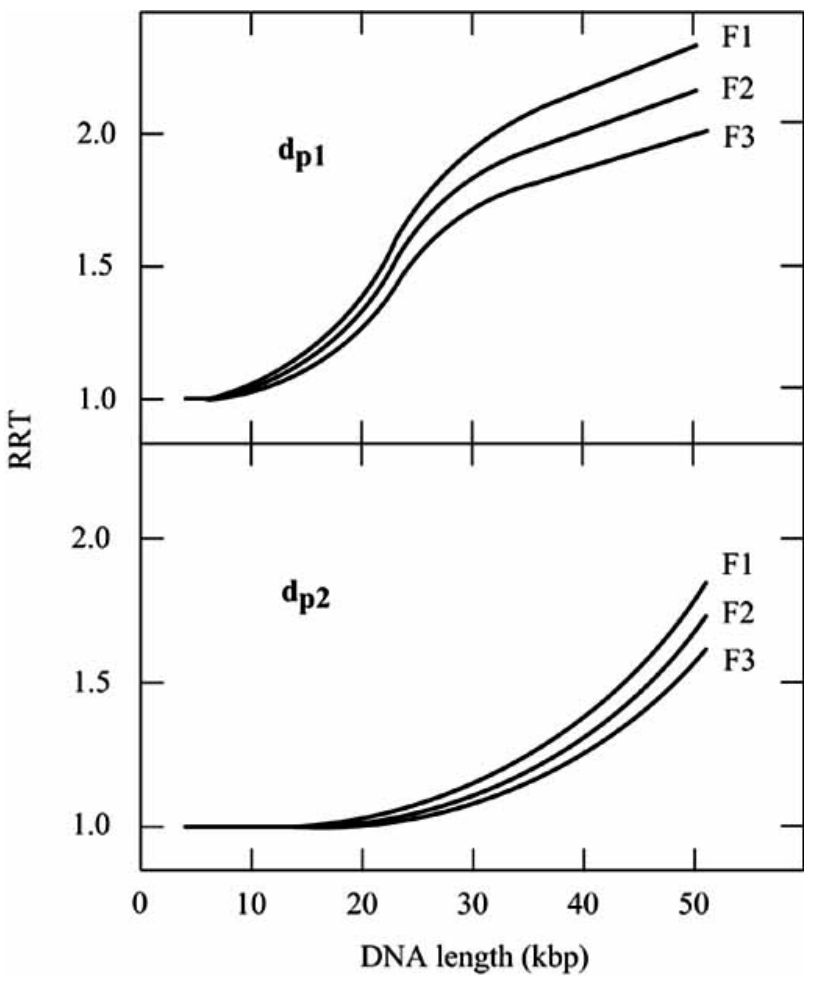

4b

Fig. (4). RRT in slalom chromatography [27-33]. (a) RRT for different mobile phase viscosities and double stranded DNA fragments with different lengths: DNA1 length > DNA2 length > DNA3 length. (b) RRT for different double stranded DNA lengths and different flow rates: $\mathrm{F} 1>\mathrm{F} 2>\mathrm{F} 3$. The particle diameter $d_{p l}$ is lower than the particle diameter $d_{p 2}$.

With the use of a faster flow, Fig. (4b), the steady-state extension, $L$, of a DNA molecule increases. Consequently, the number of pores occupied by this elongated fragment [33], as well as the reorientation time (the time needed for a chain completely aligned along a direction to completely reorient itself and go in a new direction), also increase [32], higher values of $R R T$ being obtained (Eqs. (2) and (3)).

Guillaume et al. [33] developed a semi-theoretical model including the influence of the particle size and flow rate on the RRT. The model describes well the experimental data and allows the establishment of the best operating conditions in order to optimize the resolution. Guillaume et al. [33] referred that "...the progression of the DNA fragments through the close column packing follows the flow direction and is like a snake edging is way into long grass".

\section{HDC AND SC INVENTIONS AND APPLICATIONS}

\subsection{Latexes}

HDC (this designation was suggested by Small [2]) can be applied to different colloidal problems, for instance polymer latexes $[2,3]$. The determination of particle size (in the end product or during emulsion polymerization), polydispersity, rates of particle growth and particles aggregation [3] motivated Small [51] during the development of the first invention related with HDC.

For the separation of polystyrene latexes, Small [51] disclosed the use of PCHDC columns containing polystyrene beads, glass beads, etc. The beads particle diameter and the size of the polystyrene latexes were located in the approximate range $5-100 \mu \mathrm{m}$ and $0.01-5 \mu \mathrm{m}$, respectively [51].

Silebi and Dos Ramos exemplified the use of CHDC in the separation of different submicron soft latexes. In this invention [52] the fused silica open capillaries had internal diameters located in the range $4-60 \mu \mathrm{m}$ and lengths $1-50$ $\mathrm{m}$.

Recently, the field of particle size distribution characterization and measurement has experienced a renaissance. PCHDC and CHDC (also known by capillary hydrodynamic fractionation [52-54]) had an important role in the referred revitalization [55]. PCHDC was invented in the laboratories from Dow Chemical Company [51] and it took ten years to be transferred from a laboratory method into a commercial instrument. In the field of particle size distribution, the commercialization of PCHDC failed in the market place due to the occurrence of particle deposition in the packed columns [55]. Obviously, PCHDC columns are less disposed to clogging during the fractionation of soluble molecules. In CHDC there is much less propensity for the particles to deposit in the open capillary. The commercial embodiment of CHDC has become available from Matec Applied Sciences after the works from Silebi and Dos Ramos [5254], this instrument being widely used nowadays [56-62].

PCHDC and CHDC are very popular techniques among latex producers. In the invention from Salminen et al. [63] it is disclosed the use of polymer particles having two separate maxima of the particle size distribution (bimodal latex dispersions). The invention provides low viscosity and high solids bimodal dispersions. These dispersions can be used in the formulation of paper coatings having low viscosity for high shear rates, high solids, high water retention and good 
runability in the coating machines. The combination of large $(90-150 \mathrm{~nm})$ and small $(13-50 \mathrm{~nm})$ particles was critical in order to obtain the desired dispersion/coating properties.

Daniele et al. [64, 65] suggested new processes for obtaining aqueous polymer dispersions with polymodal distributions of the polymer sizes. These dispersions had low viscosities and high solid content, reducing the transportation/storage costs and power consumption to remove the water during the application of sealant formulations, adhesives, varnishes, paints, cement-based-mortars and coatings, and products for processing paper, textiles and leather. The content of micro-aggregates and macro-aggregates was low and it was suggested the following particle size distribution: $0-40 \%$ mean diameter of less than $300 \mathrm{~nm} ; 0-40 \%$ mean diameter 300 - $500 \mathrm{~nm} ; 40-95 \%$ mean diameter greater than $500 \mathrm{~nm}$. The weight distributions of the sizes of the polymer particles were determined using CHDC [64, 65].

In order to improve the performance of aqueous emulsion polymers Verbrugge and Hurley invented a polymeric surfactant to stabilize - prevents phase separation - the prepared insoluble polymer particles [66]. Due to the low levels of surfactant and small particle size, the resultant emulsion polymers are useful for glossy finishes, ink binders, overprint varnishes and industrial coatings [66]. The emulsion polymer particle size (measured by HDC) was less than $100 \mathrm{~nm}$ [66].

Lee et al. [67] discovered that in alkaline environments non-carboxilated latexes swell (swelling was estimated using HDC [67]) at temperatures higher than the glass transition temperature of the polymer. Therefore, hollow polymer particles were obtained, these particles being useful as opacifying plastic pigments, since the hollow structure in latex particles scatters light more efficiently than the uniform density particles counterparts. Hollow latex particles can be applied in paint and paper coating, reducing the need for expensive pigments, such as titanium dioxide.

\subsection{Rubber Particles}

There are many applications where rubber particles are dispersed in matrices, such as thermoplastics, in order to modify the physical properties of the matrix [68, 69]. The number and the size of the rubber particles present in the matrix considerably affect the amount of the desired physical modification. Langhorst and Henry disclosed a method to estimate the distribution according to size of the rubber particles contained in a given matrix $[68,69]$. In the referred method, the matrix was dissolved in dimethylformamide but the non continuous phase (rubber particles) was not affected by the matrix solvent; the solvent/matrix solution containing the dispersed rubber particles were added to dimethylformamide (the mobile phase); the rubber particles were separated according to size using non-aqueous PCHDC [69]. Langhorst and Henry [68, 69] referred that the particle size distribution determined using a Coulter counter can be highly inaccurate if some or all of the dispersed particles have diameters which are less than $0.5 \mu \mathrm{m}$. Transmission electron microscopy also produces inaccurate particle size distributions, being relatively costly [68, 69].

In a typical polymerization process [69], the monomer and the rubber particles are fed into a polymerization system.
This system mixes the rubber particles with monomer and polymerises the monomer. Finally, the polymerized composition is delivered to the extrusion system [69].

The chromatographic system can detect anomalies in samples collected from the polymerisation system. If the concentration of rubber particles (deficiency or overabundance) is not the desired, the chromatographic system can signal the input control system in order to correct the anomaly. If the range of particle sizes is undesirable, the chromatographic system can shut all the system down, thereby preventing waste [69].

The impact resistance of various polymer compositions can be raised by the inclusion of elastomeric (i.e., rubbery) polymer substrates into the matrix (continuous phase) of the composition [70]. This fact is also referred in various patents released by General Electric Company, related with polycarbonate thermoplastic compositions, these compositions being useful in the manufacture of articles and components for automotive parts and electronic appliances [71- 76]. Large $(>0.5 \mu \mathrm{m})$ rubber particles offer high impact resistance but reduce the gloss, the opposite being observed with small rubber (such as polybutadiene) particles [70].

The monovinylidene aromatic polymer compositions from Vanspeybroeck et al. [70] had a good balance of gloss and impact properties. In order to achieve that, the inventors suggested a trimodal particle size distribution: 0.05-0.3 $\mu \mathrm{m}$ (at least 33\%, based on the total rubber content), 0.15-0.4 $\mu \mathrm{m}$ $(15-67 \%)$ and $0.3-2 \mu \mathrm{m}$ (0-35\%). The particle size distribution from the rubber particles can be determined using HDC [70-76].

\subsection{Hollow and Solid Micro (Nano) Particles}

Microcapsules or nanocapsules can be found in foods, cosmetics, printing, agricultural products, detergents, biomedical applications, etc. [77]. In micro (nano) encapsulation it is promoted the formation of a polymeric matrix or shell around the droplets or particles of a given core substance. There are different mechanisms of releasing the core material to the liquid that surrounds the micro (nano) capsule, the most common being the controlled-release (widely applied in the controlled delivery of drugs). In this mechanism the encapsulated substance is released at a relatively slow rate over a prolonged time [77], the most desirable release profile being a constant release with time (zero-order kinetics). The release profiles for micro (nano) capsules are closely tight to their size and size distribution, the rate of release decreasing with the increase of the capsule size [7881].

Polymeric matrixes (microspheres or nanospheres) containing dispersed medication can also be used in controlled drug release [22, 82-85]. Berkland et al. [82] fabricated different diameter microspheres containing various loadings of rhodamine $\mathrm{B}$ or piroxicam (non-steroidal anti-inflammatory drug). Overall, larger microspheres provided lower release rates and concave-upward release profiles while smaller microspheres provided higher release rates and concave-downwards release profiles. Consequently, it was possible to choose mixtures of microspheres with different size (and proper drug loadings) to generate desired release 
profiles, in particular the important constant release with time (zero-order release) [82].

Atomic force microscopy (AFM), photon correlation spectroscopy (PCS) and HDC were employed by Yegin and Lamprecht [22] in the size determination of lipid nanoparticles. AFM imaging was considered insufficient and the performance of PCS and HDC were comparable in terms of simple size determination. Moreover, HDC allowed the discovery of micellar systems and an accurate size classification of multi-modal samples [22].

Petramec [77] released a patent suggesting many applications for micro (nano) capsules uniformly distributed in a liquid but it was referred that the most economically interesting application of the invention was related to petroleum products. Fuel additives fulfil a variety of functions (corrosion inhibitors, antioxidants, pour point depressants, emulsifying agents, control of deposits in combustion chambers, etc.), being used in cars, planes, power plants and heaters. Some of these additives are not compatible and can adversely react with fuel components or pipelines and thanks. Therefore, some additives are used in quantities higher than the necessary to cancel out the losses caused by the referred undesirable interactions [77].

Chemical substances contained by capsules can be suddenly "on command" released, this release being caused by various stimuli, for instance a temperature increase of the liquid medium [77]. In order to avoid the undesirable interactions referred above, additives that, for instance, enhance fuel performance during combustion, should stay encapsulated until the fuel approaches the engine and then be "on command" released (temperature increase) [77]. After the release, additives will be properly distributed in the liquid medium if the capsules are uniformly distributed in the same medium. To attain a uniform distribution of the capsules in the liquid, with a given density, the capsules density and capsules size must be accurately controlled. Bielski and Carter [77] referred that HDC may be used in order to obtain the desired narrow size distribution.

Microcapsules obtained by a spray-drying process may be used as echogenic contrast agents in ultrasound imaging [86-90]. Generally, the wall-forming material is proteinaceous and the core contains a gas [86-90]. Sanjiv and Johnson proposed the use of the referred capsules (filled with air) for the detection of myocardial perfusion abnormalities [86]. The capsules were generally administrated by injection into a suitable vein or into an artery, depending on their size. Microcapsules with diameter 6-15 $\mu \mathrm{m}$ were suggested in order to target the myocardium tissue having the perfusion defect [86].

Iron oxide crystals coated with thin layers of polysaccharides are useful as contrast agents in magnetic resonance imaging (MRI) [81]. Fahlvik et al. [81] referred that the potential targets of the contrast agents are many, depending on the administration route and the physicochemical properties from the particulate material, in particular the particle size and surface characteristics. The inventors [81] suggested the use of particles with diameter inferior to $300 \mathrm{~nm}$. The size of the contrast agents referred above (ultrasound imaging and MRI) may be controlled by HDC [86-91].

\subsection{Synthetic Polymers and Biopolymers}

HDC can be used in the size fractionation of organic and water soluble synthetic polymers [4-13, 52, 92, 93] or biopolymers [5, 9, 11, 17-20, 52]. Prud'homme et al. [93] developed a method for characterizing the molecular weight and molecular weight distribution of ultra-high molecular weight water soluble polymers (polyacrylamide, poly-acrylamide/acrylic acid copolymers, etc.). To enhance the detectability of the polymer samples, the polymers back-bones were tagged with a fluorescent compound. The samples were eluted through a PCHDC column containing non-porous particles with diameter of $15 \mu \mathrm{m}$ and detected by a fluorescence detector, the signal being then recorded. The calibration curve (obtained using polyacrylamide standards) and the recorded signal allowed the characterization of the samples (molecular weight and molecular weight distribution). The inventors $[92,93]$ suggested the application of the developed method to biopolymers (xanthan and DNA).

$\mathrm{SC}$ is a very promising chromatographic size-dependent DNA fractionation, likely to compete with electrophoretic techniques [32]. This new fractionation technique has a number of advantages over capillary gel electrophoresis. It usually takes less than 30 minutes, and reproducible, accurate, and quantitative data can be obtained easily by using a conventional high-performance liquid chromatography system [27].

In the pioneer work from Hirabayashi and Kasai [26] it was reported the separation of DNA fragments with sizes ranging from 10 to $40 \mathrm{kbp}$. Meanwhile it was found that DNA length, particle size, flow rate, temperature and viscosity are critical factors in SC [27-33]. This evolution allowed the separation of DNA fragments with sizes ranging from 4.4 to $50 \mathrm{kbp}$ [27-33]. Nevertheless, the resolution ability of SC is still inferior to that of capillary gel electrophoresis [30, 31].

In order to reach optimum peak separations during the separation of double stranded DNA fragments by SC Gjerde et al. [94-96] suggested the use of a multivalent cation capture resin placed upstream of the separation column. Additionally, in the patents released by Transgenomic Inc. [94-96] it is also suggested the use of liquid chromatography systems made of titanium, stainless steel or polymeric material, these components being treated in order to prevent the release of multivalent cations and, therefore, protecting the separation bed from multivalent cation contamination.

\section{CURRENT \& FUTURE DEVELOPMENTS}

HDC is used in the size-fractionation of many colloids and macromolecules, this technique being a very popular among polymer latex manufactures.

Using a column filled with $1 \mu \mathrm{m}$ non-porous particles, Kraak [97] performed a fast separation of a mixture of organic soluble polystyrenes in the $M w$ range $0.5-700 \mathrm{kDa}$. Such a fast separation in the referred $M w$ range is not possible with size exclusion chromatography (SEC) [97], the separation media from HDC (non-porous particles) being much more simple than the used in SEC (porous particles). 
Soon it will be possible to perform HDC size- fractionations of low $M w$ molecules using channels with very small hydraulic diameter $[9,98]$ or columns packed with very small particles. Non-porous silica particles with diameter $<1$ $\mu \mathrm{m}$ can be easily produced [97].

The use of particles in the referred size range can probably be used in SC size-fractionation of double stranded DNA fragments having sizes well bellow $5 \mathrm{kbp}$. In SC, when a DNA chain is applied to a chromatographic system, it frequently goes around the spherical obstacles; the larger the fragments, the more difficult to travel across the interstitial spaces created inside the column [33]. This sentence and similar ones seems to suggest that the tortuosity coefficient [35-37, 99] can play an important role in SC. It may be worthy to explore the influence of the referred coefficient in the retardation of the DNA molecules and SC resolution.

Having in mind the simple separation mechanisms from HDC and SC, monolithic columns [100, 101] can probably be applied to these size-fractionation techniques.

\section{REFERENCES}

[1] DiMarzio EA, Guttman CM. Separation by flow. Macromolecules. 1970; 3: 131-146.

[2] Small H. Hydrodynamic chromatography a technique for size analysis of colloidal particles. J Colloid Interface Sci 1974; 48: $147-161$.

[3] Small H. Discoveries concerning the transport of colloids and new forms of chromatography. Acc Chem Res 1992; 25: 241-246.

[4] Langhorst MA, Stanley FW, Cutié SS, et al. Determination of nonionic and partially hydrolysed polyacrylamide molecular weight distributions using hydrodynamic chromatography. Anal Chem 1986; 58: 2242-2247.

[5] Hoagland DA, Prud homme RK. Hydrodynamic chromatography as a probe of polymer dynamics during flow through porous media. Macromolecules 1989; 22: 775-781.

[6] Tijssen R, Bos J, Kreveld ME. Hydrodynamic chromatography in open microcapillary tubes. Anal Chem 1986; 58: 3036-3034.

[7] Stegeman G, Kraak JC, Poppe H. Hydrodynamic chromatography of polymers in packed columns. J Chromatogr A 1993; 657: 283303.

[8] Venema E, Kraak JC, Poppe H, Tijssen R. Packed-column hydrodynamic chromatography using 1-mm non-porous silica particles. J Chromatogr A 1996; 740: 159-167.

[9] Blom MT, Chmela E, Oosterbroek, RE, Tijssen R, Berg A. On-chip hydrodynamic chromatography separation and detection of nanoparticles and biomolecules. Anal Chem 2003; 75: 6761-6768.

[10] Mori S, Porter RS, Johnson JF. Gel permeation chromatography: on the mechanism of separation by flow. Anal Chem 1974; 46: 1599-1602.

[11] Chun MS, Park OO, Kim JK. Flow and dynamic behaviour of dilute polymer solutions in hydrodynamic chromatography. Korean J Chem Eng 1990; 7: 126-137.

[12] Liu Y, Radke W, Pasch H. Coil-stretch transition of high molar mass polymers in packed-column hydrodynamic chromatography. Macromolecules 2005; 38: 7476-7484.

[13] Liu Y, Radke W, Pasch H. Onset of the chromatographic mode transition from hydrodynamic chromatography to slalom chromatography: an effect of polymer stretching. Macromolecules 2006; 39: 2004-2006.

[14] Stegeman G, Oostervink R, Kraak JC, Poppe H, Unger K. Hydrodynamic chromatography of macromolecules on small spherical non-porous silica particles. J Chromatogr 1990; 506: 547-561.

[15] Jung KT, Shul YG. Capillary hydrodynamic fractionation studies on the crystal growth of TS-1 zeolite. J Non-Cryst Solids 2003; 316: 246-254.
[16] Mota M, Teixeira J, Yelshin A, Cortez S. Utilization of pore topology for the separation of bioparticles in a mixed-glass beads column. J Chromatogr B 2006; 843: 63-72.

[17] Peyrin E, Guillaume YC, Villet A, et al. Flow rate dependence on the biopolymer retention in Hydrodynamic chromatography. Comparison between the behaviours of proteins and plasmids. J Liq Chromatogr Rel Technol 2001; 24: 1245-1252.

[18] Guillaume YC, Thomassin M, Robert JF, Guinchard C. Peculiarities of the retention mechanism of circular and linear DNA fragments using non-equilibrium chromatography. J Liq Chromatogr Rel Technol 2001; 24: 1061-1072.

[19] Klavons JA, Dintzis FR. Millard MM. Hydrodynamic chromatography of waxy maize starch. Cereal Chem 1997; 74: 832-836.

[20] Dias RP. Transport phenomena in polydisperse porous media (in Portuguese). PhD. Dissertation, Minho University, Braga, Portugal (2007).

[21] Williams A, Varela E, Meehan E, Tribe K. Characterization of nanoparticle systems by hydrodynamic chromatography. Int $\mathrm{J}$ Pharm 2002; 242: 295-299.

[22] Yegin BA, Lamprecht A. Lipid nanocapsule size analysis by hydrodynamic chromatography and photon correlation spectroscopy. Int J Pharm 2006; 320: 165-170.

[23] Perrin FX, Masuyer CC, Truong TT, et al. Supercoiled circular DNA and protein retention in non-equilibrium chromatography. Temperature and velocity dependence: testimony of a transition. J Chromatogr A 2002; 950: 281-285.

[24] Peyrin E, Caron C, Garrel C, et al. DNA migration in hydrodynamic chromatography and slalom chromatography: evidence for a transition. Talanta 2001; 55: 291-296.

[25] Boyes BE, Walker DG, McGreer PL. Separation of large DNA restriction fragments on a size-exclusion column by a nonideal mechanism. Anal Biochem 1988; 170: 127-134.

[26] Hirabayashi J, Kasai K. Size-dependent chromatographic separation of double-stranded DNA which is not based on gel permeation mode. Anal Biochem 1989; 178: 336-341.

[27] Hirabayashi J, Ito N, Noguchi K, Kasai K. Slalom chromatography: size-dependent separation of DNA molecules by a hydrodynamic phenomenon. Biochemistry 1990; 29: 9515-9521.

[28] Hirabayashi J, Kasai K. Applied slalom chromatography: Improved DNA separation by the use of columns developed for reversedphase chromatography. J Chromatogr A 1996; 722: 135-142.

[29] Hirabayashi J, Kasai K. Effects of DNA topology, temperature and solvent viscosity on DNA retardation in slalom chromatography. J Chromatogr A 2000; 893: 115-122.

[30] Peyrin E, Guillaume YC, Grosset C, et al. Mobile-phase-viscosity dependence on DNA separation in slalom chromatography. J Chromatogr A 2000; 886: 1-7.

[31] Peyrin E, Guillaume YC, Garrel C, et al. Effect of temperature on DNA fractionation in slalom chromatography. Talanta 2000; 52: 1105-1110.

[32] Peyrin E, Guillaume YC, Villet A, Favier A. Mechanism of DNA hydrodynamic separation in chromatography. Anal Chem 2000; 72 : 853-857.

[33] Guillaume YC, Perrin FX, Guinchard C, et al. Separation in slalom chromatography: stretching and velocity dependence. Anal Chem 2002; 74: 1217-1222.

[34] Bos J, Tijseen R, Kreveld ME. Determination of the dissociation temperature of organic micelles by microcapillary hydrodynamic chromatography. Anal Chem 1989; 61: 1318-1321.

[35] Dias RP, Fernandes CS, Teixeira JA, Mota M, Yelshin A. Permeability analysis in bisized porous media: Wall effect between particles of different size. J Hydrol 2008; 349: 470-474.

[36] Dias RP, Fernandes CS, Teixeira JA, Mota M, Yelshin A. Permeability and effective thermal conductivity of bisized porous media. Int J Heat Mass Transfer 2007; 50: 1295-1301.

[37] Dias RP, Teixeira JA, Mota M, Yelshin A. Tortuosity variation in low density binary particulate bed. Sep Purif Technol 2006; 51: 180-184. 
[38] Dias RP, Fernandes CS, Mota M, Teixeira JA, Yelshin A. Starch analysis using hydrodynamic chromatography with a mixed-bed particle column. Carbohydr Polym. 2008; doi: 10.1016/j.carbpol. 2008.05.001.

[39] Dias RP, Teixeira JA, Mota M, Yelshin A. Effect of the large size ratio in particle binary mixtures on the packing porosity. Ind Eng Chem Res 2004; 43: 7912-7919.

[40] Dias RP, Teixeira JA, Mota M, Yelshin A. Preparation of controlled particulate mixtures with glass beads of different sizes. Sep Purif Technol 2004; 37: 69-80.

[41] Shingel KI. Current knowledge on biosynthesis, biological activity, and chemical modification of the exopolysaccharide, pullulan. Carbohydr Res 2004; 339: 447-460.

[42] Han JA, BeMiller JN, Hamaker B, Lim ST. Structural changes of debranched corn starch by aqueous heating and stirring. Cereal Chem 2003; 80: 323-328

[43] Hanselmann R, Burchard W. Structural properties of fractionated starch polymers and their dependence on the dissolution process. Macromolecules 1996; 29: 3277-3282.

[44] Fishman ML, Rodriguez L, Chau HK. Molar masses and sizes of starches by high-performance size-exclusion chromatography with on-line multi-angle laser light scattering detection. J Agric Food Chem 1996; 44: 3182-3188.

[45] Galinsky G, Burchard W. Starch fractions as examples for nonrandomly branched macromolecules. 4. angular dependence in dynamic light scattering. Macromolecules 1997; 30: 6966-6973.

[46] Bello-Pérez LA, Roger P, Baud B, Colonna P. Macromolecular features of starches determined by aqueous high-performance size exclusion chromatography. J Cereal Sci 1998; 27: 267-278.

[47] Han JA, Lim ST. Structural changes of corn starches by heating and stirring in DMSO measured by SEC-MALLS-RI system. Carbohydr Polym 2004; 55: 265-272.

[48] You SG, Lim ST. Molecular characterization of corn starch using an aqueous HPSEC-MALLS-RI system under various dissolution and analytical conditions. Cereal Chem 2000; 77: 303-308.

[49] Yoo SH, Jane J. Molecular weights and gyration radii of amylopectins determined by high-performance size-exclusion chromatography equipped with multi-angle laser-light scattering and refractive index detectors. Carbohydr Polym 2002; 49: 307314.

[50] Yang C, Meng B, Chen M, Liu X, Hua Y, Ni Z. Laser-light scattering study of structure and dynamics of waxy corn amylopectin in dilute aqueous solution. Carbohydr Polym 2006; 64: 190-196.

[51] Small, H.: US3865717 (1975)

[52] Silebi, C.A., DosRamos, J.G.: US5089126 (1992).

[53] Silebi CA, DosRamos JG. Separation of submicrometer particles by capillary hydrodynamic fractionation (CHDF). J Colloid Interface Sci 1989; 130: 14-24.

[54] DosRamos JG, Silebi CA. An analysis of the separation of submicron particles by capillary hydrodynamic fractionation (CHDF). J Colloid Interface Sci 1989; 133: 302-320

[55] Provder T. Challenges in particle size distribution measurement past, present and for $21^{\text {st }}$ century. Prog Org Coat 1997 ; 32: 143153.

[56] Zyl AJP, Bosch RFP, McLeary JB, Sanderson RD, Klumperman B. Synthesis of styrene based liquid-filled polymeric nanocapsules by the use of RAFT-mediated polymerization in miniemulsion. Polymer 2005; 46: 3607-3615.

[57] Kim IH, Park JH, Cheong IW, Kim JH. Swelling and drug release behaviour of tablets coated with aqueous hydroxypropyl methylcellulose phthalate (HPMCP) nanoparticles. J Control Release 2003; 89: 225-233.

[58] Charleux B, Nicolas J. Water-soluble SG1-based alkoxyamines: A breakthrough in controlled/living free radical polymerization in aqueous dispersed media. Polymer 2007; 48: 5813-5833.

[59] Stubbs JM, Sundberg DC. A round robin study for the characterization of latex particle morphology-multiple analytical techniques to probe specific structural features. Polymer 2005; 46 : 1125-1138.

[60] Shin JS, Kim JH, Cheong IW. Colloidal and thermal stability of polyaniline-coated multi-core shell polystyrene latexes prepared using sulfonated N-hydroxyethyl aniline. Synth Met 2005; 151: 246-255

[61] Zyl AJP, Roos DW, Sanderson RD, Klumperman B. The role of surfactant in controlling particle size and stability in miniemulsion polymerization of polymeric nanocapsules. Polymer 2005; 46: 3607-3615.

[62] Lee JM, Cho JE, Kim JH, Cho HK, Cheong IW. Poly(styrene/ hydroxypropyl methylcellulose phthalate) latex particles prepared by resin-fortified emulsion-polymerization. Colloids Surf A 2007; 307: $35-44$

[63] Salminen, P.J., Lazarus, E.R., Stollmaier, F.T.: WO02070615 (2002)

[64] Becchi, D., Finocchiaro, S., Lugli, M., Saija, L.M.: EP1401877 (2004).

[65] Becchi, D., Finocchiaro, S., Lugli, M., Saija, L.M.: US20077220803 (2007).

[66] Verbrugge, C.J., Hurley, S.M.: WO0022009 (2000)

[67] Lee, D.I., Mulders, M.R., Nicholson, D.J., Leadbetter, A.N.: US5521253 (1996).

[68] Langhorst, M.A., Henry, J.B.: US5183604 (1993)

[69] Langhorst, M.A., Henry, J.B.: US5372721 (1994).

[70] Vanspeybroeck, R.S., Maes, D., Galobardes, M.R., Jones, M.A., Ceraso, J.M.: WO0024823 (2000).

[71] Glasgow, K, Mullen, B., Sybert, P.D.: US20087321014 (2008)

[72] Siripure, S., Agarwal, N., Lens, J.P.: US20080015290 (2008).

[73] An, Y, Cheng, J., Jiao, H., Lin, Y., Tjahjadi, M., Yang, X. US20080004397 (2008)

[74] Siripuri, S.: US20080015289 (2008).

[75] Volkers, A.A., Belot, L.: US20080004373 (2008)

[76] Mullen, B.: US20077273917 (2007)

[77] Bielski, R., Carter, J. E.: WO0059616 (2000)

[78] Yamamoto T, Dobashi T, Kimura M, Chang CP. An approach to analysis of pigment release from microcapsules with size distribution. Colloids Surf B: Biointerfaces 2002; 25: 305-311.

[79] Chang CP, Yamamoto T, Kimura M, Sato T, Ichikawa K, Dobashi $\mathrm{T}$. Release characteristics of an azo dye from poly(ureaurethane) microcapsules. J Control Release 2003; 86: 207-211.

[80] Liu R, Huang SS, Wan YH, Ma GH, Su ZG. Preparation of insulinloaded PLA/PLGA microcapsules by a novel membrane emulsification method and its release in vitro. Colloids Surf B: Biointerfaces 2006; 51: 30-38.

[81] Liu R, Ma GH, Wan YH, Su ZG. Influence of process parameters on the size distribution of PLA microcapsules prepared by combining membrane emulsification technique and double emultion-solvent evaporation method. Colloids Surf B: Biointerfaces 2005; 45: 144-153.

[82] Berkland C, King M, Cox A, Kyekyoon K, Pack DW. Precise control of PLG microsphere size provides enhanced control of drug release rate. J Control Release 2002; 82: 137-147.

[83] Berkland C, Kyekyoon K, Pack DW. Fabrication of PLG microspheres with precisely controlled and monodisperse size distributions. J Control Release 2001; 73: 59-74.

[84] Bezemer JM, Radersma R, Grijpma DW, Dijkstra PJ, Blitterswijk CA, Feijen J. Microspheres for protein delivery prepared from amphiphilic multiblock copolymers 2. Modulation of release rate. J Control Release 2000; 67: 249-260.

[85] Freiberg S, Zhu XX. Polymer microspheres for controlled drug release. Int J Pharm 2004; 282: 1-18.

[86] Sanjiv, K., Johnson, R.A.: US5961459 (1999).

[87] Johnson, R.A., Wouw, P.A.: WO9744064 (1997).

[88] Osborne, N., Sutton, A.D., Johnson, R.A.: US20036623722 (2003).

[89] Sutton, A.D., Johnson, R.A.: US20050238586 (2005).

[90] Sutton, A.D., Johnson, R.A., James, S.P., David, H.: EP1829557 (2007) 
[91] Fahlvik, A.K., Naelig, V.A., Gundersen, H, Strande, P., Klaveness, J., Jacobsen, A.: US20016207134 (2001).

[92] Prud'homme, R.K., Stanley, F.W., Langhorst, M.A.: US4532043 (1985).

[93] Prud'homme, R.K., Stanley, F.W., Langhorst, M.A.: US4629566 (1986).

[94] Gjerde, D.T., Haefele, R.M., Togami, D.W.: EP1023306 (2000).

[95] Gjerde, D.T., Haefele, R.M., Togami, D.W.: US20026491821 (2002).

[96] Gjerde, D.T., Haefele, R.M., Togami, D.W.: US20036579459 (2003).

[97] Kraak JC. Prospects of miniaturized separation systems. Pure Appl Chem 1997; 69: 157-162.
[98] Blom MT, Chmela E, Gardeniers JGE, Tijssen R, Elwenspoek M, Berg A. Design and fabrication of a hydrodynamic chromatography chip. Sens Actuators B 2002; 82: 111-116.

[99] Fernandes CS, Dias RP, Nóbrega JM, Maia JM. Laminar flow in chevron-type plate heat exchangers: CFD analysis of tortuosity, shape factor and friction factor. Chem Eng Process 2007; 46: 825833.

[100] Eeltink S, Desmet G, Truyols GV, Rozing GP, Schoenmakers PJ, Kok WT. Performance limits of monolithic and packed capillary columns in high-performance liquid chromatography and capillary electrochromatography. J Chromatogr A 2006; 1104: 256-262.

[101] Jungbauer A, Hahn R. Polymethacrylate monoliths for preparative and industrial separation of biomolecular assemblies. J Chromatogr A 2008; 1184: 62-79. 